\title{
An Evaluation on Construction Land Intensive Use in Chengdu City
}

\author{
Zhou You \\ School of Economics \& Management, University of Sichuan Agriculture \\ 46 Xin Kang Road, Ya'an 625014, China \\ Tel: 86-187-2816-7078Ｅ-mail: Zhouyou546517129@126.com \\ Wenkuan Chen (Corresponding author) \\ School of Economics \& Management, University of Sichuan Agriculture \\ 46 Xin Kang Road, Ya'an 625014, China \\ Tel: 86-139-8017-9889Ｅ-mail: cwk9889@ yahoo.com.cn \\ Liu Song \\ School of Economics \& Management, University of Sichuan Agriculture \\ 46 Xin Kang Road, Ya'an 625014, China \\ Tel: 86-138-8244-6030Ｅ-mail: songliu1987@163.com
}

Received: December 14, 2010

Accepted: January 12, 2011

doi:10.5539/jsd.v4n3p235

The research is financed by Sponsors: Modern ecological agriculture planning in Southwest (CR1002)

\begin{abstract}
Facing the national conditions that there is a huge number of the population many people but it has very limited land resources. Also the cultivated land resource is shortage. In the process of urbanization, how to improve the land use efficiency? How to intensive utilization of urban land? Discuss these problems for reasonable use limited land resources have important practical significance. What is a city intensive utilization of land? And how to evaluate the urban land use intensive degree? This paper adopts DE Phil method and analytic hierarchy process (ahp), from the present situation of Chengdu city land using, carrying on the intensive use appraisal to Chengdu 05-09 year construction land, including qualitative analysis and quantitative analysis. Draw Chengdu urban land intensive use level in general is increasing trend, Including 2006 intensive degree is maximum, 05 year, 07-09 year are in relatively intensive use phase. Accordingly forward the countermeasures and proposals to increase the level of land intensive use Chengdu city.
\end{abstract}

Keywords: Chengdu, Construction land, Intensive Use, Evaluation

\section{Introduction}

Land, as the "mother of all things on earth", is the foundation of human existence and development. In all natural resources, land resources will play an important and irreplaceable role in the economic and social development. However, with the development of economy and society, the acceleration of the urbanization process, and the increasing population growth, the conflict between humans and the land is further intensified. Thus we must seek a way to make full and rational use of the land. And achieve sustainable development with economy, society, resources and environment all in harmony. The evaluation of the level of intensive use urban land use is good to arrange the regional land use reasonably. Nowadays, experts has do some related researches on the evaluation of the level of intensive use urban land use and also make many achievements in this area. The scholars carry out a more comprehensive research on the urban land intensive utilization both in theory and quantitative evaluation. Zhao Li, Fu Mei Chen, YAN Xue-shi (2007) adopted the method of AHP and fuzzy comprehensive assessment to evaluate the land intensive degree. As a result, the authors got the status of land intensive use in Youngling, which could give us a helpful reference for further development. Ren Yan-min, Zhang Jia- gong, Zhang Zhengsheng (2007) Based on methods of Analytic Hierarchy Process and taking the cities in the Pearl River Delta as examples, four grades index such as land input, land output, land economic benefit and land continuable use, are chosen to form the index system of urban land intensive use, analyzing the level of urban land intensive use in the Pearl River Delta. The result of the analysis is graded. Urban land use in the corn of the Pearl River Delta is more intensive than in the periphery of the Pearl River Delta, and then gives some suggestions on improving the level of urban land intensive use in the Pearl River Delta. Song Hong - Mei, Hou Hu - ping et al (2007). From society, economy and environment, then established evaluation index system from three aspects of above, adopting the method of entropy to determine weight, choosing integrative plus weight to make certain the degree 
of ULIU. Shang Tian-cheng Gao Bin-bin LI Xiang-peng Zhang-Yan (2009) provided a new approach for the evaluation of China's urban land intensive use according to the problems above. Construct evaluation index system. And adopted to improve the evaluation index weight which is determined by the analytic hierarchy process (AHP).Furthermore, specific evaluation process is given. Finally, acting as an example, the urban land utilization situations in Beijing, Tianjin, Shanghai, and Chongqing are analyzed by the new method.

\section{General situation of the studying area}

Chengdu is located in the central of Sichuan province and in the Sichuan basin west margin of Chengdu plains (Figure1), between east $102^{\circ} 54^{\prime} \sim 104^{\circ} 53^{\prime}$ diameter and Latitude $30^{\circ} 5^{\prime} \sim 31^{\circ} 26^{\prime}$. The city's length is $192 \mathrm{~km}$ from east to west, width is $166 \mathrm{~km}$ from north to south, the total area is 12,121 square kilometers and cultivated area is 648 million mu. To the end of 2009, Chengdu' population is 1139.63 million, and it is in the fourth after Beijing, Shanghai, Chongqing in the national mega cities. Among urban population is 520.86 million, County population is 618.77 million; the agricultural population is 510.25 million, the non-agricultural population is 629.38 million. Chengdu 2009 urban land area is 2129 square kilometers; construction land area is 418.23 square kilometers and is only $19.6 \%$ of the land area. After 60 years of development, especially in reform and opening up 30 years development, Chengdu's comprehensive strength is enhanced markedly, people's living is great improvement, Chengdu status has improved significantly in the province, southwest, and country. In the 2009, the production value reached 4502.6 billion Yuan, it ranks sixth in China's 15 deputy provincial city. Nearly 20 years, Chengdu have perfected a loop, the second ring road, 3rd ring road, inner loop, Funan River integrated control and Tianfu square engineering. Subway no.1 begins to operations and other subway line will open in succession. Urban appearance and ecological environment is obviously improved, with the city features become more prominent.

\section{Data sources and research methods}

\subsection{Data sources}

In order to reflect Chengdu's intensive degree of the urban land use, this paper selected Chengdu's social, economic and ecological aspects data of urban land use from 2005 to 2009, the statistics annals of Chengdu city and the statistics annals of Sichuan province.

\section{2 research methods}

\subsubsection{The definition of urban land intensive use}

Land use is people according to the characteristics and function of land resources, around certain purposes, eventually realize of land resource of the development, utilization, protection and renovation, its essence is to reflect the changing relationship between human and land. ( Caiwen ,Wantao,Wangxiong, 2006,pp,137-139).Urban land intensive use level is refer to the city land on unit area of investment and use conditions(Yang jianbo,Wang li, 2007,pp,40-44). Through adopting certain land use technical means and economic management measures, which can make intensive use of urban land closer to the best degree of intensity.

\subsubsection{Determining the evaluation index system}

Land use system requirements of the dynamic characteristics of the construction land-use evaluation index of must contain dynamic index, must use aspects from the dynamic evaluation (Liumingliang, Shenyan, pp, 164-166). Intensive itself has capital, human resources, material intensive and save concept. Therefore, index factor selection on basic need not absolute index. In intensive construction land use in the macro assessment, land use intensity, land investment intensity etc evaluation levels will usually be involved(Yangyanfei,Chensonglin,2008,pp,4-5).According to the definition of urban land intensive use level as well as the existing land intensive use evaluation index system ,following the science and operability consideration, comprehensive and leading fulty, systematicness and stratigraphic sex principle. Combining with Chengdu land utilization characteristics and taking into account the availability of data to determine the indexes. From land utilization strength, land investment degree, land output efficiency and sustainable land use intensity 4 aspects has constructed the city level of land intensive use evaluation index system (table 1).

\subsubsection{Index weight determination}

This paper uses the analytic hierarchy process(AHP), it is based on the theory of system level-oriented principle set up, it is a destination to complex problem decomposition into several levels; it is in the original problem than simple level gradually analysis comparison; it is the people's subjective judgment with number of forms to express and processing; it is a qualitative analysis and quantitative analysis of multi-factor evaluation method; it also belongs to the comprehensive evaluation method of a kind. First using of expert scoring on selected indicators of construction land in Chengdu to rate, and then according to the situation, using Yaahp software to determine the use of weight (table 2).

\subsubsection{Data standardization processing}

Based on the original data and index calculation formula, first calculate each index layer in the index. Then according to the formula below, the data were normalized, namely the dimensionless processing (Kishindo P.Land, 1994, pp.319 - 326).Finally draw each index layer after standardization value (table 3). 
Formula:

$x_{i j}^{\prime}=x_{i j} / x_{j(\max )}(i=1,2,3, \ldots, 22 ; j=1,2,3,4)$

$x_{i j}$ _tandardization; ${ }_{i j}$ —original data; ${ }^{x_{(\max )}}$ —Each index of the maximum;

3.2.4 Intensive degree calculation.

Land intensive degree refers to the unit area land input, it can use the material form or ideology indicators to measure. The index level data first will be standardized, through the weight value table 2 and the formula below to calculate comprehensive value, again according to the following formula to compute the year of intensive degrees. ECL represents intensive degrees, $0 \leq \mathrm{ECL} \leq 1$, if ECL approximates to 1(Wang tiecheng, Wu qun, $\mathrm{He}$ shouchun, 2007).The land use intensive degree is higher. According to the calculation which is obtained by calculating and Chengdu construction land use change and development, intensity of construction land was graded. The following is ECL value in different range of the meaning represented.

$0 \leq \mathrm{ECL}<0.3-$ Extensive use;

$0.3 \leq \mathrm{ECL}<0.5-$ More appropriate use;

$0.5 \leq \mathrm{ECL}<0.7 —$ Relative intensive use;

$0.7 \leq \mathrm{ECL}<1 —$ Intensive use.

Through the multiplication weighted score deriving evaluated object's comprehensive evaluation value.

The formula is:

$$
E C L_{i}=\sum U_{i} \times M_{i}
$$

$E C L_{i}$ Represents intensive land utilization degree composite index, $U_{i}$ represents a numerical evaluation items, $M_{i}$ and represents the evaluation project weights. In addition:

$$
U_{i}=\sum V_{i} \times W_{i}
$$

$V_{i}$ represents a evaluation index (after standardization); $W_{i}$ represents the evaluation indexes weights.

\section{Result analysis}

According to above developed evaluation model and calculated intensive degrees ,from intensive degree change and the influence factors of the two aspects were analyzed(Yantao,Liuxuelu,Luozhihen, 2009,pp, 15-21).

\subsection{Intensive variation analysis}

We can be seen from the graph (table 4), Construction land intensive degree is higher and belong to intensive use in 2006. The main reason is this year compared to last year land investment intensity is very largely, GDP is high, Tertiary industry employment is not much. Construction land intensive degree belongs to relative intensive use in 2005, 2007, 2008, 2009, but 2007, 2008 and 2009 are near the intensive use phase. The main reasons are as follows: firstly, Chengdu is located in plain area and in industrial comparative developed area; Secondly, Chengdu location advantage and industrial advantage is obvious; Thirdly Chengdu economy is relatively developed, Chengdu urban infrastructure is more perfect, and Chengdu land development, utilization rate is higher;Lastly,during the tenth five-year plan, Chengdu economic keep healthy growing steadily, whatever economic volume or all aspects of social and economic development has made rapid progress.

\subsection{The analysis of influence factors}

Each years of intensive construction land degrees is affected by land utilization strength, land investment intensity, land output and sustainable land use intensity of comprehensive effect .Land investment intensity on the intensive degree of influence is bigger, 05 years of intensive degree is low. The main reason is that investment intensity is not enough, with the improvement of investment intensity, intensive degree is increasing. Land output and intensive degree change is basically the same, construction land intensive degree directly affect the land output level. In the high degree of intensive construction land use, we can obtain very good land profit and get higher financial income and regional industrial output value on the growth. Each years of land use strength also determines the size of intensive construction land degrees, when the land utilization strength at higher stage, intensive degree is bigger also On the contrary then is smaller (figure 2).

4.2.1 Land use intensity on the intensive degree impact analysis

From figure 3 can be seen, in land use intensity, population density is in stability growth. Per capita quantity standard of construction land is in smooth small and medium-sized amplitude variation, population growth and construction land use elastic coefficient variation amplitude is bigger, they were less than 1 , this shows that 
population growth rate is less than construction land growth and construction land intensive tends to slow direction (figure 3).

4.2.2 Land investment intensity on the intensive degree impact analysis

From figure 4 can be seen ,in 2005 to 2009, investment intensity with the development of economy is increasing ,this caused the construction land tends to intensive use. Fixed assets investment and construction land use growth elasticity coefficient value is negative in 2009, because of its construction land use acreage decrease and fixed assets investment on unit area increased. In 2006, the fixed assets investment and construction land use growth elasticity coefficient value is 1 , because the 2006 investment is very big, which makes the growth rate of fixed asset investment growth rate far greater than the area of construction land. In the Labor input side, labor inputs are increased year by year (figure 4).

4.2.3 Land output efficiency on the intensive degree impact analysis

From figure 5 can be seen, in 2005 to 2009, Unit construction land and tertiary industry output value and unit construction land revenues are increased year by year. Unit construction land and tertiary industry output value in 2005 is 18228.176 Yuan/square kilometers, in 2009 it is 38547.677 Yuan/square kilometers. Unit construction land fiscal revenue in 2005 is 12123.43 Yuan/square kilometers, in 2009 it is 30590.092 Yuan/square kilometers. Tertiary industry production and construction land use growth elasticity coefficient of variation amplitude is bigger, in 2009, it is a negative value, because its construction land use acreage is decreasing ,but tertiary industry output value and finance income are rising ( figure 5).

4.2.4 Sustainable land use intensity on the intensive degree impact analysis

From figure 6 can be seen, greenbelt area per capita variation amplitude is smaller; green coverage rate is increasing year by year, and green coverage rate is very high, this shows Chengdu much attention to afforest environment this problem, which are inseparable with the garden city. Per capita roads area is also increased year by year (figure 6).

Through the above analysis, it can be obtained, in influencing degree of intensive construction land 4 projects layer ,land investment intensity of intensive degree influence is the biggest of all. Land investment intensity, fixed investment, fixed assets investment and construction land use growth elasticity coefficient and intensive utilization degree are inseparable. From the land output, secondary and tertiary industries and construction land use growth elasticity coefficient, unit construction land fiscal revenue opposite index of intensive degree of influence is bigger. So, to combine the construction land quantity change, from employment, fiscal revenue, and industrial value aspects of intensive degree researched and analyzed

\section{Countermeasures and Suggestions}

\subsection{To strengthen land utilization and management.}

For all batch not levy of land, levy but not for leeway, unused land, for all batch not levy, levy and did not offer, for but unused land thorough cleaning statistics, item by item, registration, establish the parcel database, strengthens to the land management.

\subsection{To strengthen the idle land management.}

Land idle more 2 years, according to law, and resolutely gratis, rearranging use; land idle above 1 years dissatisfaction of 2 years, according to the land transfer price $20 \%$ levy an idle land fee.

\subsection{Three-dimensional utilization of land resources.}

Establishing the three-dimensional concept of land use, in keep unified planning, under the precondition of save land space; accomplish truly an inch of land one inch gold.

\subsection{To technology and planning to land.}

Developers in developing land will make great efforts to improve the existing enterprise land concentration degree, project content of science and technology and land utilization, realize from extensive to intensive transformation.

\subsection{Using advanced techniques}

Using remote sensing modern technology, carrying out evaluation analysis and the dynamic monitoring; Using Chengdu construction land tracking system, implementing whole regulatory for the land transfer contract execution and transfer of decision implementation; Through unit GDP and the scale of fixed asset investment growth of new construction land cost assessment method, assessmenting economical and intensive utilization of land.

\section{References}

Caiwen,Wantao,Wangxiong. (2006). Urban land intensive use potential evaluation research. Scientific progress and countermeasures, 2006,(1):137-139.

Liu mingliang,Shenyan. (2008). Urban construction land intensive use evaluation research — with changsha for example. Jiangxi agricultural journal, 2008,20(10):164-166. 
Kishindo P.Land. (1994). reform and agricultural development:the case Lesotho. Joumal of Rural Development, 1994,13(3),319-326.

Ren Yan-min, Zhang Jia- gong, Zhang Zheng- sheng. (2007). The Evaluation of Land Intensive Use Based on Analytic Hier ar chy Process. Guangdong land science.2007,06(03): 20-24.

Shang Tian-cheng ,Gao Bin-bin ,Li Xiang-peng, Zhang Yan. (2009). Urban Land Intensive Utilization Evaluation Based on AHP and Entropy Method. Journal of UESTC.Dec.2009,Vol.11,No.6:6-9

Song Hong - Mei, Hou Hu - ping. (2007). Research on Evaluation of Urban Land Intensive Utilization. Resource Development \&Market 200723 (2):116-180

Wang tiecheng, Wu qun,He shouchun. Urban construction land intensive use evaluation research ——In wuxi city as an example [D].

Yang jianbo,Wang li. (2007). urban land intensive use level research. journal of land and resources, technology management 2007,24 (3) : 40-44.

Yantao, Liuxuelu,Luozhihen. (2009). Lanzhou city land use structure optimization study. Guangdong agricultural science, 2009,02 (15) : 15-21 .

Yangfei,Chensonglin. (2008). Fujian construction land intensive use evaluation. Guangdong land science, 2008,7(05):4-5.

Zhao Li, Fu Mei Chen, Yan Xue-shi. (2007). Based on AHP and Fuzzy Comprehensive Assessment Method Evaluating Land Intensive Use at Town Level. Resource Development \&Market.2007, 23(9):791-794.

Table 1. Urban construction land intensive use level evaluation index system

\begin{tabular}{|c|c|c|}
\hline $\begin{array}{l}\text { Target } \\
\text { layer }\end{array}$ & Rule layer & Index layer \\
\hline \multirow{12}{*}{$\begin{array}{l}\text { Urban } \\
\text { Land } \\
\text { Intensive } \\
\text { use } \\
\text { level }\end{array}$} & \multirow{3}{*}{$\begin{array}{l}\text { Land } \\
\text { utilization } \\
\text { strength(B1) }\end{array}$} & Population density $(\mathrm{C} 1)$ \\
\hline & & Population growth and construction land use elastic coefficient (C2) \\
\hline & & Per capita construction land(C3) \\
\hline & \multirow{3}{*}{$\begin{array}{l}\text { Land } \\
\text { investment } \\
\text { degree(B2) }\end{array}$} & Unit construction land investment in fixed assets(C4) \\
\hline & & Unit construction land labor inputs(C5) \\
\hline & & $\begin{array}{l}\text { Fixed assets investment and construction land use growth elasticity } \\
\text { coefficient (C6) }\end{array}$ \\
\hline & \multirow{3}{*}{$\begin{array}{l}\text { Land } \\
\text { output } \\
\text { efficiency(B3) }\end{array}$} & Unit construction land second and third industry output (C7) \\
\hline & & $\begin{array}{l}\text { Second and third industry production and construction land use growth } \\
\text { elasticity coefficient }(\mathrm{C} 8)\end{array}$ \\
\hline & & Unit construction land finance income (C9) \\
\hline & \multirow{3}{*}{$\begin{array}{l}\text { Sustainable } \\
\text { land } \\
\text { intensity(B4) }\end{array}$} & Greenbelt area per capita $(\mathrm{C} 10)$ \\
\hline & & Green coverage $(\mathrm{C} 11)$ \\
\hline & & Per capita roads area (C12) \\
\hline
\end{tabular}

Table 2. Urban construction land indexes weights

\begin{tabular}{cccc} 
Rule layer & Weight & Index layer & Weight \\
& & C1 & 0.2767 \\
B1 & 0.1539 & C2 & 0.4060 \\
& & C3 & 0.3173 \\
B2 & C4 & 0.3514 \\
& 0.3455 & C5 & 0.2002 \\
& & C6 & 0.4484 \\
B3 & C7 & 0.3214 \\
& 0.2079 & C8 & 0.4092 \\
B4 & C9 & 0.2694 \\
& & C10 & 0.3664 \\
& & C11 & 0.3453 \\
& & C12 & 0.2883 \\
\hline
\end{tabular}


Table 3. Index layer standardization value

\begin{tabular}{rcccccccccccc}
\hline Index & \multirow{2}{*}{ C1 } & C2 & C3 & C4 & C5 & C6 & C7 & C8 & C9 & C10 & C11 & C12 \\
Year & & & & & & & & \\
2005 & 0.9208 & 1 & 0.9559 & 0.3460 & 0.7593 & 0.1269 & 0.4729 & 0.0760 & 0.3963 & 0.8438 & 0.9799 & 0.8247 \\
2006 & 0.9447 & 0.6693 & 0.9334 & 0.4817 & 0.7637 & 1 & 0.5671 & 1 & 0.4028 & 0.8281 & 0.9799 & 0.8307 \\
2007 & 0.9752 & 0.0911 & 0.9503 & 0.4996 & 0.8728 & 0.0253 & 0.6632 & 0.1137 & 0.7972 & 0.8125 & 0.9802 & 0.8300 \\
2008 & 0.9658 & 0.0577 & 1 & 0.6518 & 0.9119 & 0.0508 & 0.7381 & 0.0480 & 0.8482 & 1 & 0.9948 & 0.9607 \\
2009 & 1 & -0.1235 & 0.9387 & 1 & 1 & -0.0858 & 1 & -0.1037 & 1 & 0.8906 & 1 & 1 \\
\hline
\end{tabular}

Table 4. Chengdu level of intensive construction land use comprehensive evaluation value

\begin{tabular}{ccccccc}
$\begin{array}{c}\text { Index } \\
\text { Year }\end{array}$ & B1 & B2 & B3 & B4 & ECL & Intensivism extent \\
2005 & 0.96 & 0.33 & 0.29 & 0.89 & 0.58 & Relatively intensive use \\
2006 & 0.83 & 0.77 & 0.70 & 0.88 & 0.80 & Intensive Use \\
2007 & 0.61 & 0.36 & 0.47 & 0.86 & 0.62 & Relatively intensive use \\
2008 & 0.61 & 0.37 & 0.55 & 0.99 & 0.63 & Relatively intensive use \\
2009 & 0.53 & 0.51 & 0.55 & 0.96 & 0.67 & Relatively intensive use \\
\hline
\end{tabular}

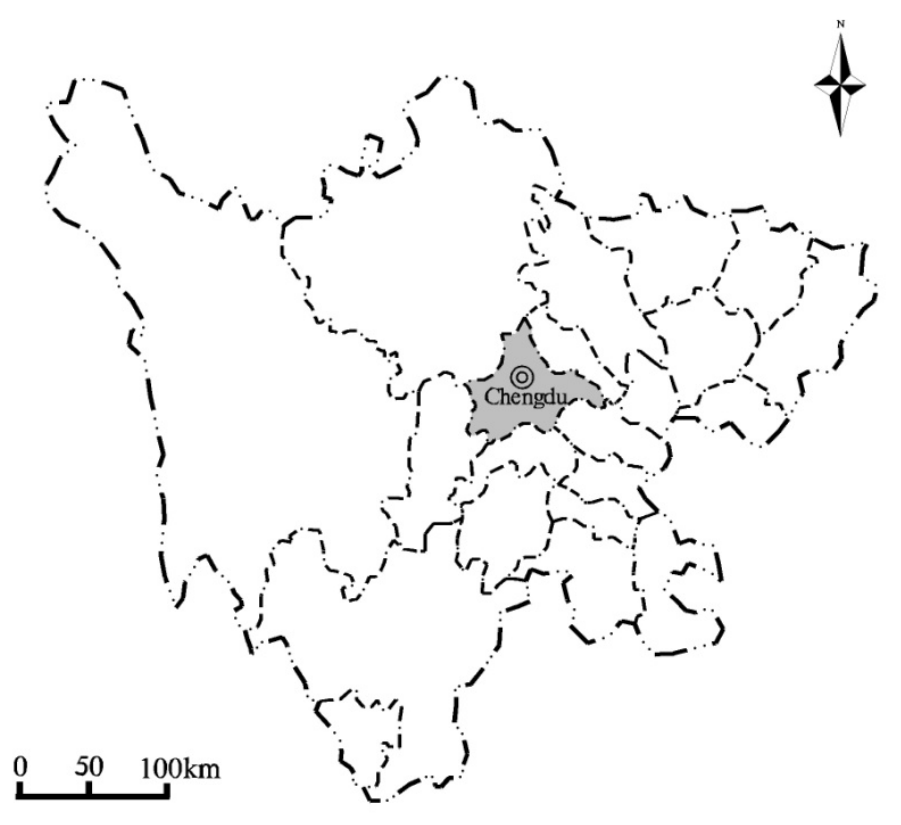

Figure 1. The location of Chengdu City in Sichuan province

Note: the city of Chengdu is bolded in gray 


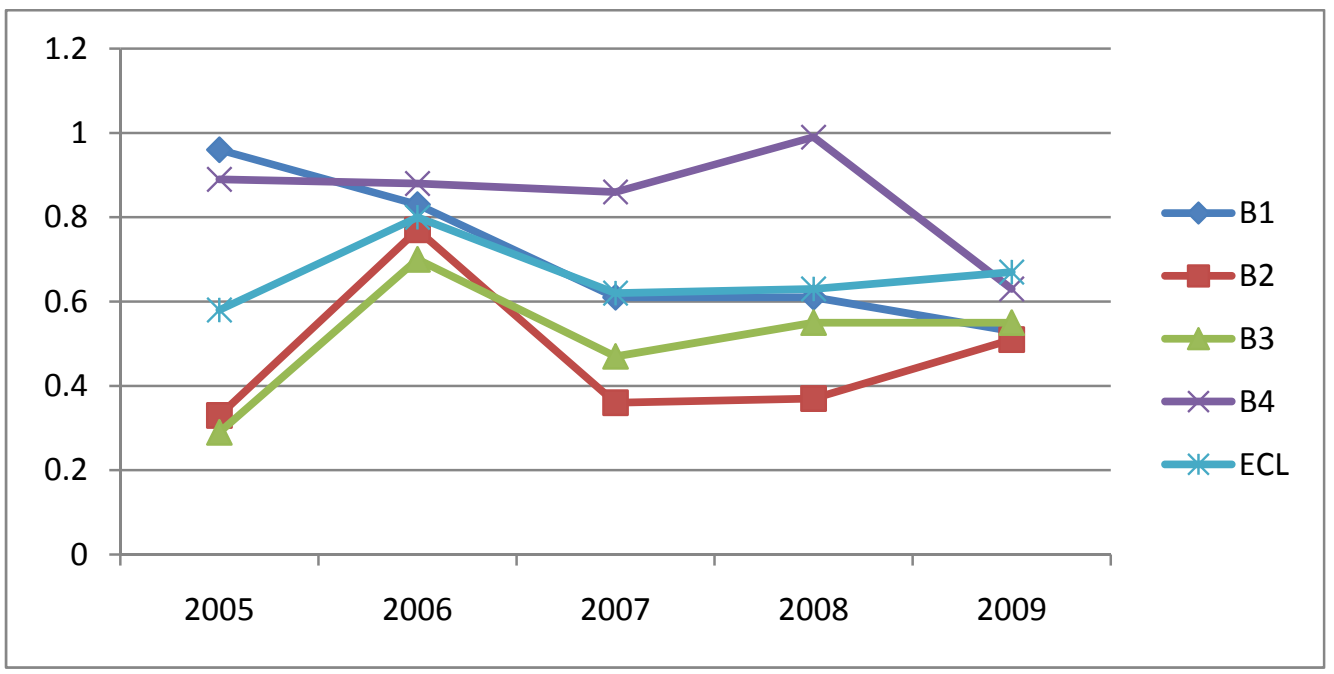

Figure 2. the changes in construction land use intensity of Chengdu City

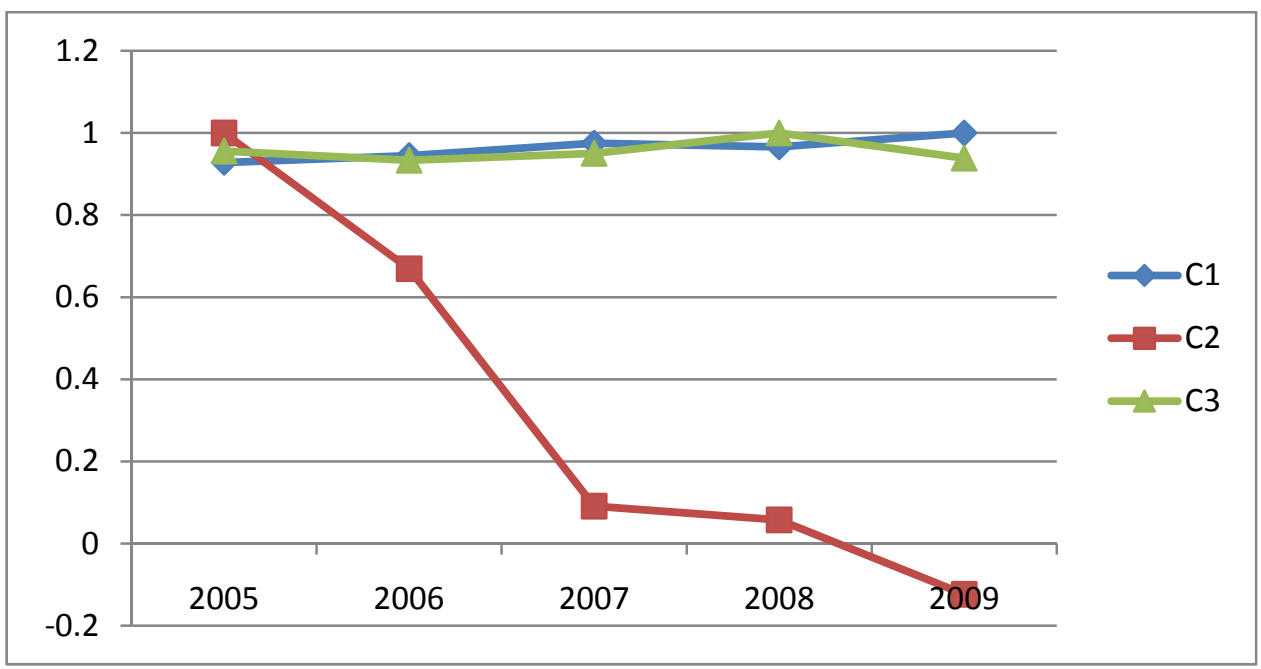

Figure 3. The analysis in the impact of factor in land-use intensity

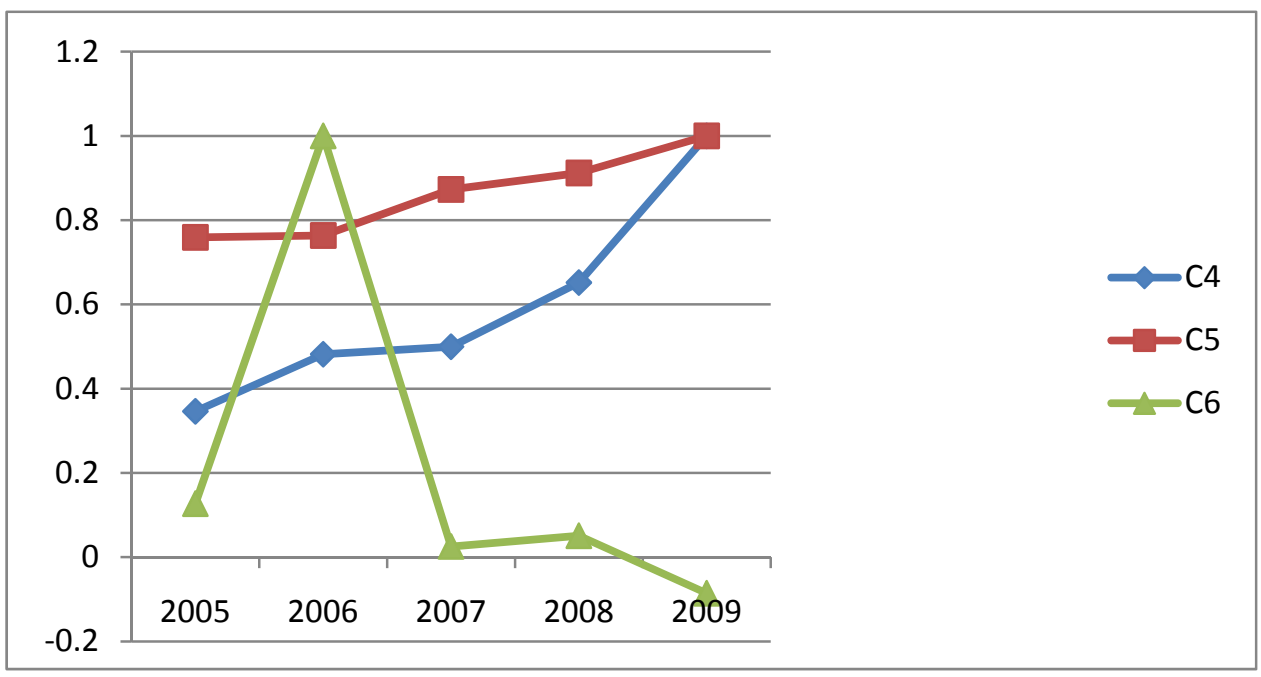

Figure 4. The analysis in the impact of factors in intensity of land 


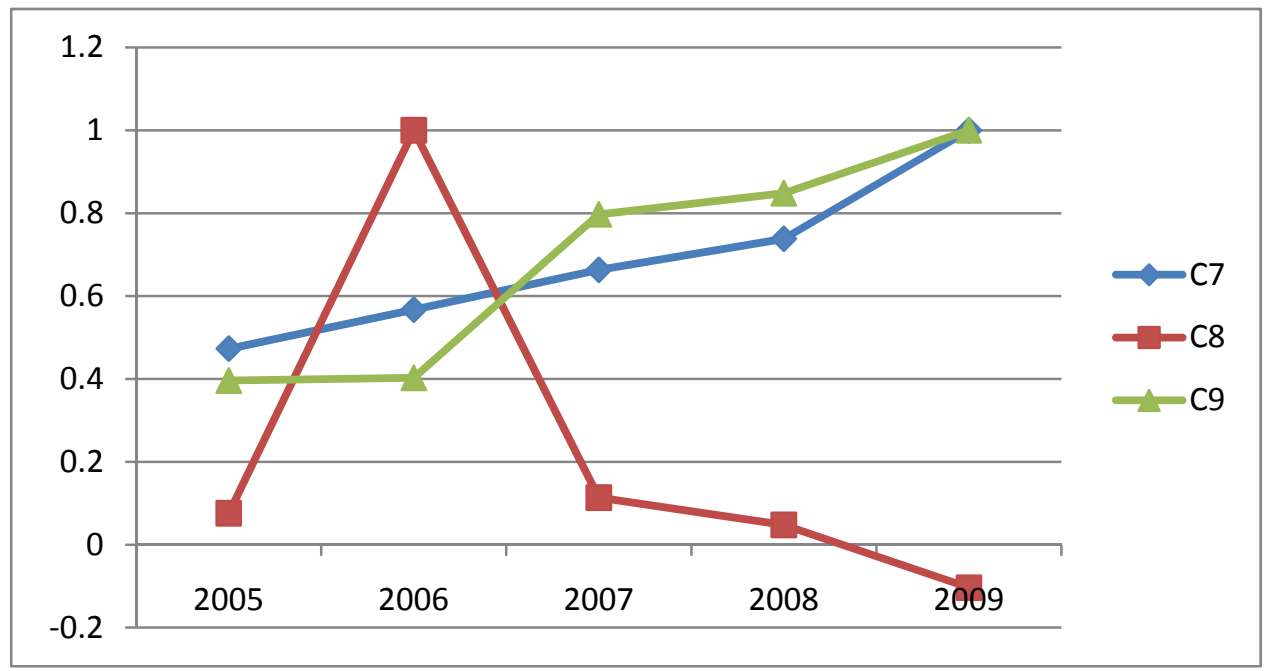

Figure 5. The analysis in the impact of factors in land-output ratio

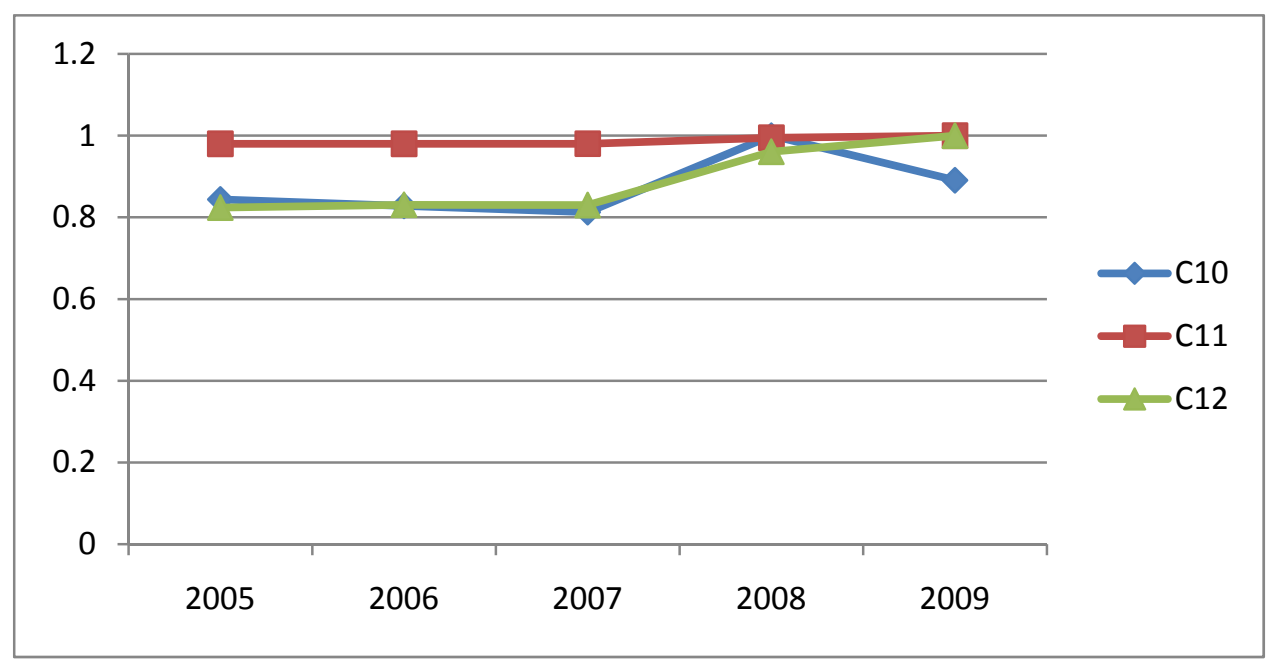

Figure 6. Sustainable land use strength analysis of influence factors 